\title{
Advantages and difficulties in culturing human pluripotent stem cells in growth factor-defined serum-free medium
}

\author{
Miho Kusuda Furue • Daiki Tateyama \\ Masaki Kinehara • Jie Na • Tetsuji Okamoto • \\ J. Denry Sato
}

Received: 25 March 2010 /Accepted: 5 April 2010 /Published online: 29 April 2010 / Editor: J. Denry Sato

(C) The Author(s) 2010. This article is published with open access at Springerlink.com

\section{Dear Editor,}

Serum- and feeder-free culture conditions have received a great deal of attention for culturing human embryonic stem (hES) cells or induced pluripotent stem (iPS) cells although hES/iPS cells are still most commonly maintained on inactivated mouse embryonic fibroblast feeders (MEF) in medium supplemented with FBS (Thomson et al. 1998; Reubinoff et al. 2000), or proprietary replacements, such as

M. Kusuda Furue $\cdot$ D. Tateyama $\cdot$ M. Kinehara

Laboratory of Cell Cultures, Division of Bioresources,

National Institute of Biomedical Innovations,

Osaka 567-0085, Japan

M. Kusuda Furue ( $\square)$

Laboratory of Cell Processing,

Institute for Frontier Medical Sciences, Kyoto University,

Kyoto 606-8507, Japan

e-mail: mkfurue@nibio.go.jp

J. Na

School of Medicine, Tsinghua University,

Beijing, China

\section{T. Okamoto}

Department of Molecular Oral Medicine and Maxillofacial

Surgery, Division of Frontier Medical Sciences,

Graduate Science School of Biomedical Sciences,

Hiroshima University,

Hiroshima 734-8553, Japan

J. D. Sato

Mount Desert Island Biological Laboratory,

Salisbury Cove, ME 04672, USA

J. Na

The Centre for Stem Cell Biology,

The University of Sheffield,

Sheffield, S10 2TN,

United Kingdom knockout serum replacement (KSR) together with fibroblast growth factor-2 (FGF-2) (Amit et al. 2000; Draper et al. 2004). Use of culture media containing undefined or undisclosed components has limited the development of applications for pluripotent cells because of our lack of knowledge of their responses to specific cues that control self-renewal, differentiation, and lineage selection. Therefore, a defined serum-free medium consisting of minimum essential components for culturing hES/iPS cells could contribute to advances in the field.

Previously, we have developed a defined growth factorsupplemented serum-free medium, hESF9, for the culture of human ES cells on a type I collagen substrate without feeders (Furue et al. 2008). This medium consists of hESF basal medium supplemented with heparin and only four protein components: insulin, transferrin, albumin conjugated with oleic acid, and FGF-2 (10 ng/ml). Under these culture conditions, FGF-2 promotes proliferation of hES cells in a concentration-dependent manner. Heparin, which is known to enhance the activity of FGF, also promotes proliferation of hES cells in a concentration-dependent manner in the absence of FGF-2 suggesting that endogenous FGF-2 is produced by hES cells. In conventional cultures with KSR-based medium, the proliferative effects of FGF-2 or heparin are not detectable although it is well known that FGF-2 supports hES cell growth. Thus, a defined serum-free medium consisting of minimum essential components could aid in elucidating hES/iPS cell responses to specific cues that control self-renewal, differentiation, and lineage selection.

The modern era of serum-free growth began in the mid1970s when Izumi Hayashi and Gordon Sato (1976) defined conditions for growth of a rat pituitary cell line in a hormonally defined serum-free medium that did not alter cell phenotypes or cell growth. N2 supplements for neural 


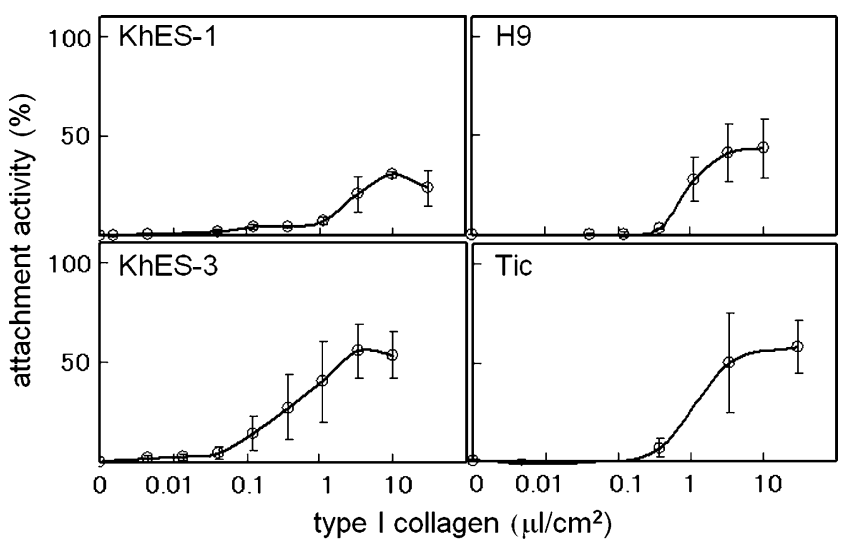

Figure 1. Attachment and proliferation of hES and iPS cells on type I collagen. The attachment of hES/iPS cells to ECM components was measured by the procedures followed by Fassler and Meyer (1995). Briefly, a 96-well microplate (Corning Costar, Corning, NY) was coated with each adhesion molecule at $37^{\circ} \mathrm{C}$ for $3 \mathrm{~h}$. hES/iPS cells were seeded at confluent density $\left(3 \times 10^{6}\right.$ cells cm$\left.{ }^{-2}\right)$ on type I collagen (Nitta Gelatin, Inc.) coated plates in hESF9 (Cell Science \& Technology Institute, Inc.). After $3 \mathrm{~d}$, the attached cells were fixed and stained for $30 \mathrm{~min}$ with $0.4 \%$ crystal violet (Sigma) in methanol. After the plate was washed and dried, a solution (1\% acetic acid and $30 \%$ ethanol in water) was added to the wells to dissolve the crystal violet. The absorbance of $595 \mathrm{~nm}$, which indicated the concentration of the dissolved crystal violet, was measured with a microplate reader (model 550; Bio-Rad, Hercules, CA). Each graph shows the percentage of the attached cells on type I collagen in hESF9 relative to the attached cells on fibronectin (Sigma) as 100\% as all the cell lines attached to fibronectin in hESF9. Bar=SE $(n=3)$.

cells were developed by Bottenstein and Sato (1979). Later, we described a variety of serum-free media that can be used to propagate and analyze differentiated cells (Barnes and Sato 1980; Sato 1987; Furue et al. 1994; Okamoto et al. 1996; Sato et al. 2002). Serum contains variable amounts of hormones, soluble growth and differentiation factors, attachment factors, and undefined components. Also MEFs secrete a variety of nutrients or growth factors most of which have not been identified. The precise formulation of KSR is not in the public domain, and although "serumfree," it is likely to contain a variety of animal products (PCT/US98/00467; WO98/30679). The formulations of several other products for serum-free culture from several companies are also proprietary. These undefined or disclosed components of the culture conditions hamper analysis of the mechanisms that control cell behavior.

However, there are several difficulties in culturing hES/ iPS cells in defined conditions without MEFs. First, propagation of pluripotent $\mathrm{hES} / \mathrm{iPS}$ cells has been difficult to achieve even in conventional culture media due to their propensity to differentiate (Skottman and Hovatta 2006; Adewumi et al. 2007) as most researchers working with $\mathrm{hES} / \mathrm{iPS}$ cells know. When cells grown to confluence are split, many differentiated cells appear in the next passage. The variability of batches of MEFs or KSR affects the tendency of cells to differentiate. The dissociation method is the most problematic. Even in conventional cell culture, imprecise handling during dissociation decreases cell survival as single hES/iPS cells cannot survive. Centrifugation at high speed decreases cell survival or promotes cell aggregation. Unless the cells are handled with care for several passages on MEFs in KSR-based medium, the cells do not survive or differentiate when transferred to feederfree cultures. We had used EDTA to dissociate hES cell colonies in the feeder-free culture method using hESF9 medium. As the attachment activity of undifferentiated hES cells is different from that of differentiated cells, the undifferentiated hES cells were able to be transferred to the next passage, which led to the successful continuous culture of undifferentiated cells. However, this method requires previous practical experience with human primary

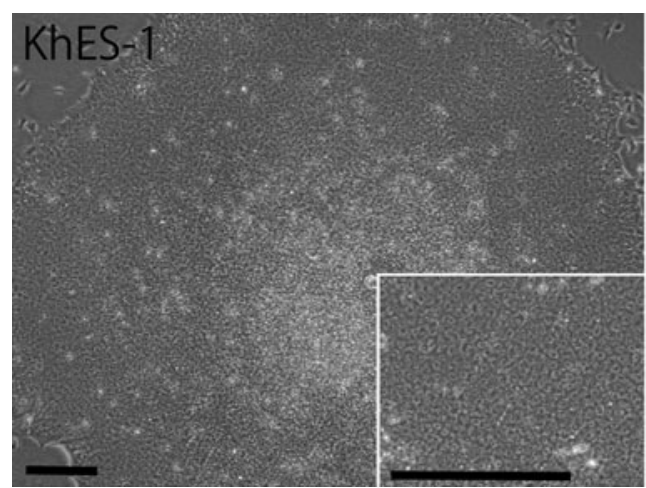

Figure 2. hES cells cultured on fibronectin in hESF9 medium. Phasecontrast microphotographs of KhES-1 at passage 16 and KhES-3 at passage 6 cultured on fibronectin in hESF9 medium. After $2 \mathrm{~d}$, the KhES-1 cells and KhES-3 cells (from Kyoto University) cultured on MEF in KSR-based medium were passaged by the routine procedure onto the new MEF; the medium was changed to hESF9 medium, and then the cells were cultured on MEF for more than $4 \mathrm{~d}$. Previously, we

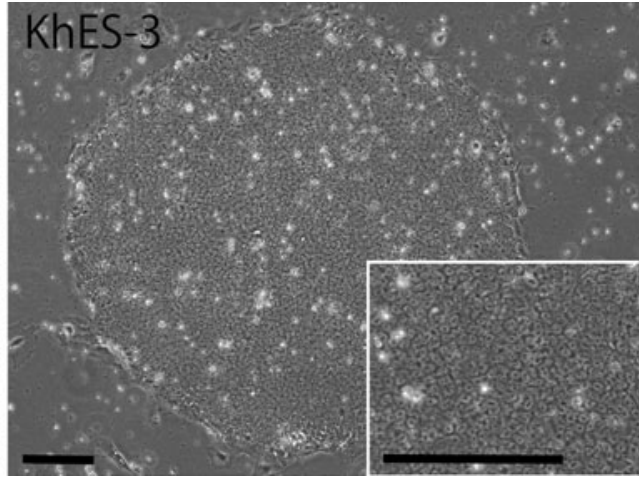

dissociated the hES cells with EDTA, but some of cell lines could not survive after the dissociation with EDTA. Then, we have utilized $1 \mathrm{U} /$ $\mathrm{ml}$ dispase (Roche Applied Science) for approximately $1 \mathrm{~min}$ at $37^{\circ} \mathrm{C}$ to dissociate the hES/iPS colonies into the small clumps. The cells were washed twice at $20 \mathrm{~g}$ and then seeded on fibronectin-coated flask (Corning Costar) in hESF9 medium. 
cell cultures. As hESF9 medium consists of minimum essential components, improper handling greatly affects cell viability and culture outcome.

Second, there are variations in the characteristics of hES/ iPS cell lines as most of the researchers working on hES/ iPS cells have come to realize. hES cell lines, Shef1, Shef5, and HUES1 cultured in the University of Sheffield were able to attach to type I collagen and grow well in hESF9 medium (Furue et al. 2008). However, we found that attachment activity of the KhES-1 line (Nakatsuji 2005), which was established in Kyoto University, to type I collagen seemed low, suggesting that there is a difference between the cell lines in their attachment ability. Owing to regulatory issues for hES cell importation into Japan, we were unable to directly compare KhES-1 cells with Shef1 or HUES1. We have examined the attachment and growth activity of other hES lines (KhES-3 from Kyoto University, Kyoto, Japan; H9 from National Stem Cell Bank, WiCell, Madison, WI) and the MRC-5-derived iPS cell line Tic (JCRB 1331, JCRB Cell Bank, Osaka, Japan), which was established in the National Center for Child Health and Development, on type I collagen (Nitta Gelatin, Osaka, Japan) in hESF9 medium (Cell Science \& Technology Institute, Sendai, Japan). The results show that there is a difference between hES/iPS cell lines in attachment activity to type I collagen. This result suggests that there is a difference among cell lines in integrin signaling (Fig. 1).

Based on these findings, we have modified the culture protocol and tried to culture KhES-1 and KhES-3 cell lines on fibronectin (Sigma, St. Louis, MO) in hESF9 medium without feeders (Fig. 2). Matrigel, a basement membrane preparation from the Engelbreth-Holm-Swarm mouse tumor, is often used for feeder-free culture for hES/iPS cells with MEF-conditioned medium (Draper et al. 2004). However, it contains a complex and ill-defined mixture of fibronectin, laminin, type IV collagen, entactin, and heparan sulfate proteoglycans, and various growth factors such as FGF-2, EGF, PDGF, and NGF (Yang et al. 2003). Ludwig et al. (2006) have reported that in place of matrigel, a combination of collagen IV, fibronectin, laminin, and vitronectin supported robust, long-term proliferation of human ES cells in their chemically defined medium TeSR1. We have previously reported by using defined serum-free culture conditions for mouse embryonic stem (mES) cell that integrins regulate $\mathrm{mES}$ cell self-renewal. $\mathrm{mES}$ cells remained undifferentiated when cultured on type I and type IV collagen or poly-D-lysine whereas they differentiated when cultured on laminin or fibronectin where LIF-induced self-renewal signaling was decreased (Hayashi et al. 2007). Now, we are investigating the role of integrins in the pluripotency of hES/iPS cells.

For robust cultures, we have further modified the culture protocol. We have used $1 \mathrm{U} / \mathrm{ml}$ dispase (Roche Applied
Science, Indianapolis, IN) to dissociate the cell colonies and washed the dispase with the medium supplemented with recombinant human albumin $(1 \mathrm{mg} / \mathrm{ml}$, Millipore, Bedford, MA). If differentiated cells appear in the culture, addition of low concentration of activin $(2 \sim 10 \mathrm{ng} / \mathrm{ml}, \mathrm{R} \& \mathrm{D}$ Systems, Minneapolis, $\mathrm{MN}$ ) or middle concentration of noggin (10 20 ng/ml, R\&D Systems) seems also to inhibit the differentiated cell growth as previously reported (Beattie et al. 2005; James et al. 2005; Vallier et al. 2005; Wang et al. 2005). However, addition of these growth factors confounds the analysis of the actions of other exogenous factors. We are using hESF9 medium to develop a drug screening test.

It would be convenient if the cell culture novice could propagate and passage any type of cell without difficulty. Unfortunately, this is currently not the case for undifferentiated hES/iPS cell lines. Although serum has proved to be a universal medium supplement that allowed the isolation and characterization of a few normal diploid cell lines and numerous abnormal transformed cell lines over the years, the use of serum or other undefined medium components impedes our ability to understand cell responses to controlled environmental stimuli. There are advantages and disadvantages to culturing hES/iPS cells under defined serum-free culture conditions, and the suitability of any particular medium depends on the purpose of the experiment.

Acknowledgments We thank Prof. P.W. Andrews for his valuable comments and discussion. We thank Hiroko Matsumura, Midori Hayashi, and Yutaka Ozawa for excellent assistance. This study was supported by a grant from the Ministry of Health, Labor and Welfare of Japan to M.K.F., by a grant from the Nipro Corp. and Itochu Corp. to M.K.F., by grants-in-aid for Japan Science and Technology Agency to M.K.F., by grants-in-aid for Scientific Research from the Ministry of Education, Culture, Sports, Science and Technology of Japan to M. K.F. and T.O., and by a Short-Term Fellowship from the Japan Society for the Promotion of Science to J.D.S.

Open Access This article is distributed under the terms of the Creative Commons Attribution Noncommercial License which permits any noncommercial use, distribution, and reproduction in any medium, provided the original author(s) and source are credited.

\section{References}

Adewumi O.; Aflatoonian B.; Ahrlund-Richter L.; Amit M.; Andrews P. W.; Beighton G.; Bello P. A.; Benvenisty N.; Berry L. S.; Bevan S.; Blum B.; Brooking J.; Chen K. G.; Choo A. B.; Churchill G. A.; Corbel M.; Damjanov I.; Draper J. S.; Dvorak P.; Emanuelsson K.; Fleck R. A.; Ford A.; Gertow K.; Gertsenstein M.; Gokhale P. J.; Hamilton R. S.; Hampl A.; Healy L. E.; Hovatta O.; Hyllner J.; Imreh M. P.; Itskovitz-Eldor J.; Jackson J.; Johnson J. L.; Jones M.; Kee K.; King B. L.; Knowles B. B.; Lako M.; Lebrin F.; Mallon B. S.; Manning D.; Mayshar Y.; McKay R. D.; Michalska A. E.; Mikkola M.; Mileikovsky M.; Minger S. L.; Moore H. D.; Mummery C. L.; Nagy A.; Nakatsuji N.; O'Brien M.; Oh C. S. K.; Olsson C.; 
Otonkoski T.; Park K. Y.; Passier R.; Patel H.; Patel M.; Pedersen R.; Pera M. F.; Piekarczyk M. S.; Pera R. A.; Reubinoff B. E.; Robins A. J.; Rossant J.; Rugg-Gunn P.; Schulz T. C.; Semb H.; Sherrer E. S.; Siemen H.; Stacey G. N.; Stojkovic M.; Suemori H.; Szatkiewicz J.; Turetsky T.; Tuuri T.; van den Brink S.; Vintersten K.; Vuoristo S.; Ward D.; Weaver T. A.; Young L. A.; Zhang W. Characterization of human embryonic stem cell lines by the International Stem Cell Initiative. Nat. Biotechnol. 25: 803-816; 2007.

Amit M.; Carpenter M. K.; Inokuma M. S.; Chiu C. P.; Harris C. P.; Waknitz M. A.; Itskovitz-Eldor J.; Thomson J. A. Clonally derived human embryonic stem cell lines maintain pluripotency and proliferative potential for prolonged periods of culture. Dev. Biol. 227(2): 271-278; 2000.

Barnes D.; Sato G. Serum-free cell culture: a unifying approach. Cell 22: 649-655; 1980.

Beattie G. M.; Lopez A. D.; Bucay N.; Hinton A.; Firpo M. T.; King C. C.; Hayek A. Activin A maintains pluripotency of human embryonic stem cells in the absence of feeder layers. Stem Cells 23: 489-495; 2005 .

Bottenstein J. E.; Sato G. H. Growth of a rat neuroblastoma cell line in serum-free supplemented medium. Proc. Natl. Acad. Sci. USA 76: $514-517 ; 1979$.

Draper J. S.; Moore H. D.; Ruban L. N.; Gokhale P. J.; Andrews P. W. Culture and characterization of human embryonic stem cells. Stem Cells Dev. 13: 325-336; 2004.

Fassler, R.; Meyer, M. W. Consequences of lack of beta 1 integrin gene expression in mice. Genes Dev. 9: 1896-1908; 1995.

Furue M.; Okamoto T.; Ikeda M.; Tanaka Y.; Sasaki Y.; Nishihira K.; Sato J. D. Primitive neuroectodermal tumor cell lines derived from a metastatic pediatric tumor. In Vitro Cell Dev. Biol. Anim. 30A: 813-816; 1994.

Furue M. K.; Na J.; Jackson J. P.; Okamoto T.; Jones M.; Baker D.; Hata R.; Moore H. D.; Sato J. D.; Andrews P. W. Heparin promotes the growth of human embryonic stem cells in a defined serum-free medium. Proc. Natl. Acad. Sci. USA 105: 13409$13414 ; 2008$

Hayashi I.; Sato G. H. Replacement of serum by hormones permits growth of cells in a defined medium. Nature 259: 132-134; 1976.

Hayashi Y.; Furue M. K.; Okamoto T.; Ohnuma K.; Myoishi Y.; Fukuhara Y.; Abe T.; Sato J. D.; Hata R.; Asashima M. Integrins regulate mouse embryonic stem cell self-renewal. Stem Cells 25: 3005-3015; 2007.

James D.; Levine A. J.; Besser D.; Hemmati-Brivanlou A. TGFbeta/ activin/nodal signaling is necessary for the maintenance of pluripotency in human embryonic stem cells. Development 132: 1273-1282; 2005.

Ludwig T. E.; Levenstein M. E.; Jones J. M.; Berggren W. T.; Mitchen E. R.; Frane J. L.; Crandall L. J.; Daigh C. A.; Conard K. R.; Piekarczyk M. S.; Llanas R. A.; Thomson J. A. Derivation of human embryonic stem cells in defined conditions. Nat. Biotechnol. 24: 185-187; 2006.

Nakatsuji N. Establishment and manipulation of monkey and human embryonic stem cell lines for biomedical research. Ernst Schering Res. Found. Workshop. 54: 15-26; 2005.

Okamoto T.; Tani R.; Yabumoto M.; Sakamoto A.; Takada K.; Sato G. H.; Sato J. D. Effects of insulin and transferrin on the generation of lymphokine-activated killer cells in serum-free medium. $J$. Immunol. Methods 195: 7-14; 1996.

Reubinoff B. E.; Pera M. F.; Fong C. Y.; Trounson A.; Bongso A. Embryonic stem cell lines from human blastocysts: somatic differentiation in vitro. Nat. Biotechnol. 18: 399-404; 2000.

Sato J. D.; Barnes D.; Hayashi I.; Hayashi J.; Hoshi H.; Kawamoto T.; Matsuda R.; McKeehan W. L.; Matsuzaki K.; Okamoto T.; Serrero G.; Sussman D. J.; Kan M. et al. In: Davis J. M. (ed) Specific cells and their requirements. Basic cell culture: a practical approach. Oxford University Press, Oxford, pp 227$274 ; 2002$.

Sato J. D.; Kawamoto T,.; Okamoto T. Cholesterol requirement of P3X63-Ag8 and X63-Ag8.653 mouse myeloma cells for growth in vitro. J. Exp. Med. 165: 1761-1766; 1987.

Skottman H.; Hovatta O. Culture conditions for human embryonic stem cells. Reproduction 132: 691-698; 2006.

Thomson J. A.; Itskovitz-Eldor J.; Shapiro S. S.; Waknitz M. A.; Swiergiel J. J.; Marshall V. S.; Jones J. M. Embryonic stem cell lines derived from human blastocysts. Science 282: 1145-1147; 1998

Vallier L.; Alexander M.; Pedersen R. A. Activin/Nodal and FGF pathways cooperate to maintain pluripotency of human embryonic stem cells. J. Cell Sci. 118: 4495-4509; 2005.

Wang G.; Zhang H.; Zhao Y.; Li J.; Cai J.; Wang P.; Meng S.; Feng J.; Miao C.; Ding M.; Li D.; Deng H. Noggin and bFGF cooperate to maintain the pluripotency of human embryonic stem cells in the absence of feeder layers. Biochem. Biophys. Res. Commun. 330: 934-942; 2005.

Yang J. Z.; Ho A. L.; Ajonuma L. C.; Lam S. Y.; Tsang L. L.; Tang N.; Rowlands D. K.; Gou Y. L.; Chung Y. W.; Chan H. C. Differential effects of Matrigel and its components on functional activity of CFTR and ENaC in mouse endometrial epithelial cells. Cell Biol. Int. 27: 543-548; 2003. 